\title{
The Implementation of First Order and Second Order with Mixed Measurement to Identify Farmers Satisfaction
}

\author{
Retno Ayu Cahyoningtyas*, Solimun, Adji Achmad Rinaldo Fernandes \\ Department of Statistics, Faculty of Mathematics and Natural Sciences, Brawijaya University, Malang, 65145, Indonesia
}

Received July 31, 2020; Revised October 8, 2020; Accepted November 11, 2020

\begin{abstract}
Cite This Paper in the following Citation Styles
(a): [1] Retno Ayu Cahyoningtyas, Solimun, Adji Achmad Rinaldo Fernandes, "The Implementation of First Order and Second Order with Mixed Measurement to Identify Farmers Satisfaction," Mathematics and Statistics, Vol. 8, No. 6, pp. 671 - 682, 2020. DOI: 10.13189/ms.2020.080607.
\end{abstract}

(b): Retno Ayu Cahyoningtyas, Solimun, Adji Achmad Rinaldo Fernandes (2020). The Implementation of First Order and Second Order with Mixed Measurement to Identify Farmers Satisfaction. Mathematics and Statistics, 8(6), 671 - 682. DOI: $10.13189 / \mathrm{ms} .2020 .080607$.

Copyright $\odot 2020$ by authors, all rights reserved. Authors agree that this article remains permanently open access under the terms of the Creative Commons Attribution License 4.0 International License

\begin{abstract}
The purpose of this research is to develop structural modeling with metric and nonmetric measurement scales. Also, this study compares the level of efficiency between the first order and second-order models. The application of structural modeling in agriculture is the satisfaction of farmers in East Java. The data used in this study are about perceptions by distributing questionnaires to farmers in East Java Province in 2020. The respondents in this study were 155 districts in East Java Province. Therefore, the sampling technique chosen is probability sampling, which is a proportional area random sampling. The results are obtained that the first-order model is better than the second-order model because it has the lowest MSE value and the highest $R^{2}$. The results of the path analysis for the first order and second-order models produce the same results that there is a significant positive effect between the gratitude variables on the farmer satisfaction variable. That is, the more gratitude felt by farmers, the satisfaction will be increased by East Java Farmers. On the other hand, the test results showed that demographic variables did not significantly influence gratitude variables.
\end{abstract}

Keywords First Order, Mixed Measurement, Second Order, Farmers Satisfaction

\section{Introduction}

Where the change of one variable is assumed to result in changes in other variables, besides it is also related to the relationship between variables and also the model of indicators using simultaneous [25]. Based on the measurement process, variables can be categorized into manifest variables and latent variables [13]. In general, the variable is determined as a variable that cannot be accessed directly, but the variable must go through indicators that reflect and build it [10].

In a study there is a hierarchy of latent variables that only have indicators as well as items that are often referred to as first-order indicator models. Latent variables that have indicators and items are named second. In a more complex hierarchy, latent variables have dimensions, indicators, and items so they are named third, and so on [5].

Not every variable can be directly explained by indicators, indicators can also still be explained again by items, such a thing is called second-order [8]. Based on the formative and reflective indicator models, which use confirmatory factor analysis solutions and principal component analysis, the cumulative diversity is maintained at around $70 \%$, because each time conducting a factor analysis is possible to lose information about $30 \%$. If there is a second-order, then about $50 \%$ diversity is wasted in the process, meaning that when analyzed only about $49 \%$ diversity is used to explain latent variables. 
Indicator models that construct or construct variables known as formative indicator models are collected through Principal Component Analysis [11]. Different cases of latent variables with non-metric measuring scales use Nonlinear Main Component Analysis [7]. Meanwhile, the indicator model that reflects or reflects variables is called the reflective indicator model, which is used Factor Analysis [9].

Therefore, this research focuses on the innovation of modeling measurement updates, which is currently developing a lot of measurement modeling with metric measurement scale (intervals and ratios), where the measurement scale is less flexible in its use. Research is often confronted with indicators with nonmetric (nominal and ordinal) measurement scales, such as the measuring scale for demographic variables. This innovation through the development of measurement modeling by involving mixed measurement metrics (metric and nonmetric) is what will be used to complement the structural equation modeling method.

In structural modeling involving latent variables, where the data analyzed are generally obtained from the measurement process using a questionnaire, commonly referred to as measurement modeling. In addition, the renewal of this study also compares the efficiency of the first-order model with the second-order model in the process of measuring variables. The applications are used in the humanities social field, especially in the agricultural sector. This study discusses the satisfaction of farmers in East Java, using a non-metric measuring scale consisting of demographic variables and farmer gratitude.

\section{Literature Review}

Following the conceptual and operational definitions of variables, the hierarchy of latent variables varies. Some only have indicators, as well as items called first-order analysis. Then often referred to as the first-order indicator model. Latent variables that have indicators and items are called second orders. A more complex hierarchy, latent variables that have dimensions, indicators, and items are called third order, and so on. In this study, the measurement model for latent variables uses two model approaches namely first order and second order [10].

\subsection{Principal Component Analysis}

In the analysis of the main linear component, there is an input matrix, the correlation matrix. The correlation formula can be calculated using the following equation [24]:

$$
\hat{\rho}=\frac{\hat{\sigma}_{x y}}{\sqrt{\left(\hat{\sigma}_{x} \hat{\sigma}_{y}\right)}}=\frac{\sum_{i=1}^{n}\left(X_{i}-\bar{X}\right)\left(Y_{i}-\bar{Y}\right)}{\sqrt{\sum_{i=1}^{n}\left(X_{i}-\bar{X}\right)^{2} \sum_{i=1}^{n}\left(Y_{i}-\bar{Y}\right)^{2}}}
$$

Correlation matrix to calculate eigenvalues, component weights, and component scores formed:

$$
\mathbf{r}=\left[\begin{array}{cccc}
1 & r_{12} & \cdots & r_{1 m} \\
r_{21} & 1 & \cdots & r_{2 m} \\
\vdots & \vdots & \ddots & \vdots \\
r_{m 1} & r_{m 2} & \cdots & 1
\end{array}\right]
$$

The formula for calculating eigenvalues is

$$
|\mathbf{r}-\lambda \mathbf{I}|=0
$$

Whereas component weights can be seen in the following formula [1]:

$$
\left(\mathbf{X}^{\prime} \mathbf{X}-\lambda_{i} \mathbf{I}\right){\underset{\sim}{\mathbf{b}}}_{j}=0
$$

The linear equation of the main component is used to calculate the score of the main component:

$$
P C_{1}=b_{11} X_{1}+b_{12} X_{2}+\ldots+b_{1 p} X_{p}+\varepsilon_{1}
$$

The analysis of nonlinear principal component analysis is the same as linear principal component analysis. The difference in the analysis of nonlinear main components needs to do qualitative data quantification using optimal scaling techniques. Quantification is the giving of numerical values in the category of a variable.

According to [8], the input matrix in the analysis of nonlinear main components is the $\boldsymbol{G}_{j}$ matrix, thus forming the quantification matrix category as follows:

$$
\mathbf{Y}_{\mathbf{j}}=\mathbf{D}_{\mathbf{j}}^{-1} \mathbf{G}_{\mathbf{j}} \mathbf{X} \text { and } \mathbf{X}=m^{-1} \mathbf{G} \mathbf{Y}
$$

The purpose of the analysis of the main nonlinear components is to minimize the homogeneity loss function, namely:

$$
\boldsymbol{\sigma}_{M}(\mathbf{X} ; \mathbf{Y})=\frac{1}{m} \sum_{j=1}^{m} \operatorname{tr}\left(\mathbf{X}-\mathbf{G}_{j} \mathbf{Y}_{j}\right)^{\prime} \mathbf{M}_{j}\left(\mathbf{X}-\mathbf{G}_{j} \mathbf{Y}_{j}\right)
$$

The formula for calculating eigenvalues is

$$
\left|m^{-1} \mathbf{R}(\mathbf{Q})-\lambda \mathbf{I}\right|=0
$$

The formula for calculating the weights of the main nonlinear components is

$$
\underset{\sim}{a}=\left(\mathbf{Y}_{j}^{\prime} \mathbf{D}_{j}{\underset{\sim}{j} j}_{j}\right) /\left({\underset{\sim}{j} j}_{j}^{\prime} \mathbf{D}_{j} \stackrel{\sim}{\sim} j_{j}\right)
$$

Where:

$\boldsymbol{Y}$ : a collection of multiple and single category quantification, the category calculation matrix

$\boldsymbol{Y}_{\mathrm{j}}$ : count of multiple categories

$y_{j}$ : single category count vector for $h_{j}$

$\mathbf{X}$ : the average matrix of transformation data

$\mathbf{R}(\mathbf{Q})$ : correlation matrix between the combined linear scores of all matrix sets $\mathbf{Q}$ on all dimensions.

$\mathbf{Q}_{j}$ : transformation-sized data matrix $n \times m$ with 
column $q_{j}=\boldsymbol{G}_{j} y_{j}$

$q_{\sim}$ : column vector of the transformation data matrix.

Equation analysis of nonlinear main components:

$$
q_{i j}=\sum_{s=1}^{p} x_{i s} a_{j s}
$$

\subsection{Factor Analysis}

Factor analysis also involves equations, like other analytical methods. The equation in factor analysis is different from the regression. In the regression analysis, the equation is in the form of a function, but in the factor analysis, the equation is in the form of decomposition. For example, there are variables $\mathrm{X}_{1}, \mathrm{X}_{2}, \ldots, \mathrm{X}_{\mathrm{p}}$ which is spread normally with the middle-value vector $\mu$ and var-cov matrix $\Sigma[14]$.

$$
X \approx N_{p}(\mu, \Sigma)
$$

In the form of mathematical notes written as follows:

$$
\mathbf{X}=c \mathbf{F}+\varepsilon
$$

When the data input matrix is $\mathrm{S}$, the factor score is calculated using the formula:

$$
\mathbf{S}-\mathbf{F} a=c \mathbf{S}^{-1}\left(x_{j}-\bar{x}\right)
$$

When the data input matrix is $\mathrm{R}$, the factor score is calculated using the formula:

$$
\mathbf{S}-\mathbf{F} a=c^{\prime} \mathbf{R}^{-1} \mathbf{Z}_{j}
$$

An understanding of the characteristics of the reflective indicator model can be based on the basic model of Factor Analysis. Suppose there is a variable $\mathrm{X}_{1}, \mathrm{X}_{2}, \ldots, \mathrm{X}_{\mathrm{p}}$ then the factor model created is:

$$
\begin{aligned}
& X_{1}=b_{11} F_{1}+b_{12} F_{2}+\ldots+b_{1 p} F_{p}+\varepsilon_{1} \\
& X_{2}=b_{21} F_{1}+b_{22} F_{2}+\ldots+b_{2 p} F_{p}+\varepsilon_{2} \\
& \ldots \ldots \ldots \ldots \ldots \ldots \ldots \ldots \ldots \ldots \ldots \ldots \ldots \ldots \ldots \ldots \ldots \ldots \ldots \ldots \ldots \ldots \ldots \ldots \ldots \ldots \ldots \ldots \ldots \ldots \\
& X_{p}=b_{p 1} F_{1}+b_{p 2} F_{2}+\ldots .+b_{p p} F_{p}+\varepsilon_{p}
\end{aligned}
$$

In terms of measurement models, $\mathrm{Xi}$ is seen as an indicator and $\mathrm{Fi}$ is as a latent variable.

\subsection{Path Analysis}

In the path analysis, there are two variables, namely endogenous variables and exogenous variables. Exogenous variables are cause variables or that affect other variables and their diversity is determined by causes outside the model, whereas endogenous variables are effect variables or variables that are influenced by exogenous variables so that their diversity is determined by models that can be endogenous in other equations.

Endogenous variables are further divided into two namely endogenous intervening and pure endogenous. Endogenous intervening variables are variables whose diversity is explained by other variables as well as being explanatory to other variables. Meanwhile, pure endogenous variables are variables that only explain the diversity of other variables. In the path analysis, there is at least one exogenous variable $(\mathrm{X})$, one endogenous intervening variable $(\mathrm{Y})$, and one pure endogenous variable (Z) [3]. The following is a classification of the variables in this study.
a. Exogenous variables: Demografi (X1)
b. Endogenous variables
c. Endogenously pure: Farmer Satisfaction (Y1)
d. Mediation: Farmer's Gratitude (Y2)

The path diagram used in this study is shown in Figure 1.

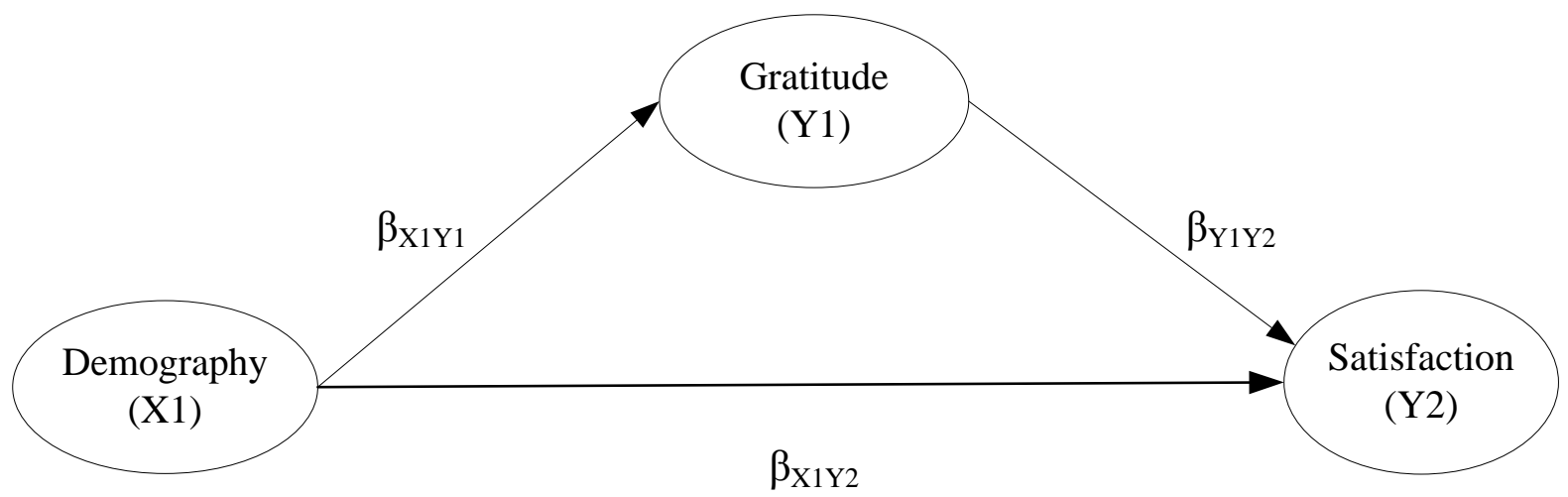

Figure 1. Research Model 
In this study suspect the path coefficient using OLS

$$
\hat{\beta}=\left(\mathbf{X}^{\prime} \mathbf{X}\right)^{-1} \mathbf{X}^{\prime} \underset{\sim}{y}
$$

There are two indicators of model validity in the path analysis, namely [10].

1) Total Determination Coefficient

$$
\begin{gathered}
R_{m}^{2}=1-P_{e 1}^{2} P_{e 2}^{2} \ldots P_{e p}^{2} \\
P_{e i}=\sqrt{1-R_{i}^{2}}
\end{gathered}
$$

Where:

$P_{e i}:$ the residual effect on each equation $(i=1,2, \ldots, p)$

$R_{i}^{2}$ : coefficient of determination in each equation

$R_{m}^{2}:$ coefficient of total determination

The greater the value of the total determination coefficient close to $100 \%$, then the model is said to be good.

\section{2) Trimming Theory}

If there is an insignificant pathway, then the pathway is removed so that a significant model can be obtained that is following the theory [5].

\subsection{Data}

Based on its measurement scales, data can be categorized into four types, including nominal, ordinal, interval, and ratio. The nominal and ordinal scales are included in the category of qualitative data (non-metric). The internal and ratio scales are included in the category of quantitative data (metric)[27], as follows:

1. Nominal data comprises of naming elements. The word of nominal derived from Latin nomos which means name. To use nominal data, it is required scores of "1" for men and " 0 " for women an alternative into numerical form by scoring, thus, it can be analyzed using statistics. An example of this case is that the change of sex category comprises of men and women by giving the scores of " 1 " for men and " 0 " for women.

2. Ordinal data is the data that does not only contain naming elements but also order elements. The word ordinal derived from the word 'order'. For instance, for the data of education that comprises elementary, middle, and high schools, constructed order and level are from the lowest to the highest.

3. Interval data is the data that does not only have naming and order elements but also interval elements. For example, there was research with students as the subject, some variables that can be categorized into interval data are the Grade Point Average (GPA) and height.

4. Ratio data is an interval data wherein the interval has a meaning (the zero is absolute). An example of this data category is the income variable.

\section{Method}

The data used in this study is about perceptions by distributing questionnaires to farmers in East Java Province in 2020. The number of respondents in this study was 155 districts in East Java Province. In East Java, there are 29 districts that are generally divided into 3 cultural regions, namely "Mataraman culture", "Arek culture", and "Madura culture". At this stage, non-probability sampling is used, namely judgment sampling, where each cultural region is represented by 5 districts which are rice paddy center areas. Samples in the form of sub-districts were taken proportionally from the districts selected in the first stage. Therefore, the sampling technique chosen is probability sampling, which is a proportional area random sampling.

\section{Result}

\subsection{First Order Model}

In the first-order analysis, the measurement of latent variables only involves indicators, which are both items as well as indicators.

\subsubsection{Measurement Model (Outer Model)}

\section{Demographic Variable}

Measurement of demographic variables using analysis of nonlinear main components. Before analyzing nonlinear main components, it must conduct category quantifications on the indicators that form. Category quantifications are used to quantify nominal and ordinal data into interval scales. Table 1 is the result of the quantification of demographic variables.

Table 1. Category Quantifications Demography Variable

\begin{tabular}{|c|c|c|c|}
\hline Indicator & Code & Name & $\begin{array}{c}\text { Category } \\
\text { Quantifications }\end{array}$ \\
\hline \multirow{4}{*}{ Gender } & 0 & Female & 0.0674 \\
\cline { 2 - 4 } & 1 & Male & -0.0013 \\
\hline \multirow{4}{*}{$\begin{array}{c}\text { Age } \\
\text { Year) }\end{array}$} & 1 & $\leq 30$ & 0.1392 \\
\cline { 2 - 4 } & 2 & $31-40$ & 0.0337 \\
\cline { 2 - 4 } & 3 & $41-50$ & -0.0128 \\
\hline \multirow{3}{*}{$\begin{array}{c}\text { Period of } \\
\text { Work } \\
\text { (Year) }\end{array}$} & 4 & $\geq 50$ & -0.0136 \\
\cline { 2 - 4 } & 2 & $-5-10$ & 0.0691 \\
\cline { 2 - 4 } & 3 & $11-20$ & 0.0205 \\
\hline \multirow{3}{*}{$\begin{array}{c}\text { Origin } \\
\text { District }\end{array}$} & 1 & $\geq 20$ & -0.0156 \\
\cline { 2 - 4 } & 2 & Madura & -0.0220 \\
\cline { 2 - 4 } & 3 & Mataraman & 0.0023 \\
\hline \multirow{2}{*}{} & & 0.0141 \\
\hline
\end{tabular}


In the analysis of the main components, an eigenvalue of 0.0484 was also generated. Furthermore, component scores can be calculated through component loading. Table 2. is the result of loading the demographic variable components.

Table 2. Component loadings Demography Variable

\begin{tabular}{|c|c|}
\hline Indicator & Component loadings \\
\hline Gender (X1.1) & 0.1179 \\
\hline Age (X1.2) & -0.4263 \\
\hline Period of Work (X1.3) & -0.4049 \\
\hline Origin District (X1.4) & 0.1663 \\
\hline
\end{tabular}

Indicators with the highest component loadings are considered more important and have a dominant role in variables. The most dominant or strongest indicator in measuring Demographic variables (X1) is the Age indicator (X1.2) with a component loading of 0.426 and Length of Work (X1.3) of 0.4049 because it has a higher value than other indicators. The diversity explained by the main nonlinear component of the total diversity is 0.2945 which means that the information that can be explained by the model for demographic variables is $29.45 \%$. So that the demographic variable measurement model can be formed as follows:

$$
\begin{gathered}
Z_{X 1}=0.1179 Z_{X 1.1}-0.4263 Z_{X 1.2}-0.4049 Z_{X 1.3} \\
+0.1663 Z_{X 1.4}
\end{gathered}
$$

\section{Gratitude Variable}

Measurement of the variable of gratitude uses factor analysis. This is because the gratitude variable has a reflective indicator, where the variable is reflected by the indicators. In principle, the latent variable data with the reflective indicator model is a factor score. The basic principle of factor analysis is to extract several common factors from a set of variables. To find out which indicator is the most powerful in reflecting/reflecting the gratitude variable, it can be seen through the factor loading value as follows:

$$
Y_{1}=-0.5727 F_{Y 1.1}+0.7303 F_{Y 1.2}+0.3723 F_{Y 1.3}
$$

Table 3. Component loadings of Gratitude Variable

\begin{tabular}{|c|c|}
\hline Indicator & Factor Loading \\
\hline Sense of Appreciation (Y1.1) & -0.5727 \\
\hline Positive Feelings (Y1.2) & 0.7303 \\
\hline Expression of Gratitude (Y1.3) & 0.3723 \\
\hline
\end{tabular}

Based on Table 3. it can be seen that the indicator that has the largest factor loading value is the Positive Feelings indicator (Y1.2) of 0.7303. Thus, it can be said that the strongest or most dominant indicator in reflecting Farmers 'Gratitude is Positive Feelings so that the positive feelings that farmers have in receiving harvests are very important for the height of farmers' gratitude. Furthermore, the diversity explained by factor loading is 0.6694 which means that the information explained by the indicators reflected by the thanksgiving variable for the first order is $66.94 \%$. Based on Table 4, the factor loading value of each indicator can be presented in Figure 2. Figure 2 is the outer model for the first-order model of the gratitude variable. The factor loading value in Figure 2 is a reflection of the gratitude variable for each of the indicators.

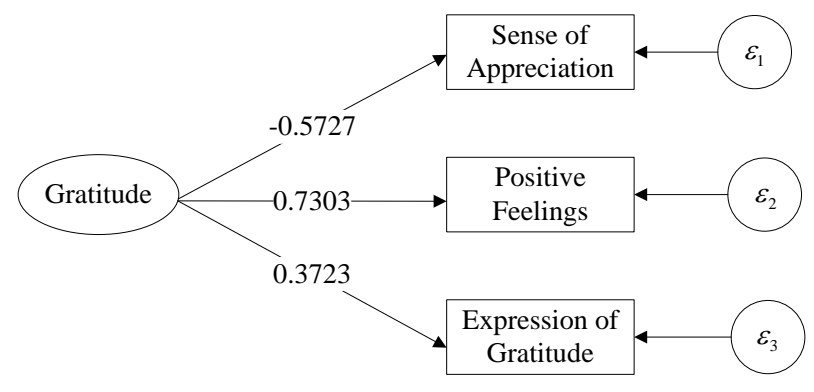

Figure 2. First Order of Outer of Gratitude Variable

\section{Farmers Satisfaction Variable}

The measurement of satisfaction variables uses principal component analysis (PCA). From the analysis results obtained component weights so that measurement models can be formed to get component scores as input from path analysis. Here is a measurement model for the satisfaction variable. To find out which indicator is the most powerful in reflecting/reflecting the gratitude variable, it can be seen through the factor loading value as follows:

$$
\begin{array}{r}
P C_{1}=-0.4750 Y_{2.1}+0.3677 Y_{2.2}-0.2352 Y_{2.3} \\
+0.1631 Y_{2.4}+0.7464 Y_{2.5}
\end{array}
$$

Table 4. Component loadings of Farmers Satisfaction Variable

\begin{tabular}{|c|c|}
\hline Indicator & $\begin{array}{c}\text { Component } \\
\text { Loadings }\end{array}$ \\
\hline Product Quality (Y2.1) & -0.4750 \\
\hline Product Price (Y2.2) & 0.3677 \\
\hline Quality of Service (Y2.3) & -0.2352 \\
\hline Emotional Factor (Y2.4) & 0.1631 \\
\hline $\begin{array}{c}\text { Ease of Getting Operational Materials } \\
\text { (Y2.5) }\end{array}$ & 0.7464 \\
\hline
\end{tabular}

Based on Table 4, it can be seen that the indicator that has the largest component loading (weight) value is the Ease of Getting Operational Materials (Y2.5) indicator of 0.7464 . So that the strongest or most dominant indicator in shaping farmer satisfaction is the ease in getting raw materials. The diversity explained by the first major component of the total diversity is 0.5067 which means that the information that can be explained by the indicators arranged for the farmer satisfaction variable at the first-order level is $50.67 \%$. 


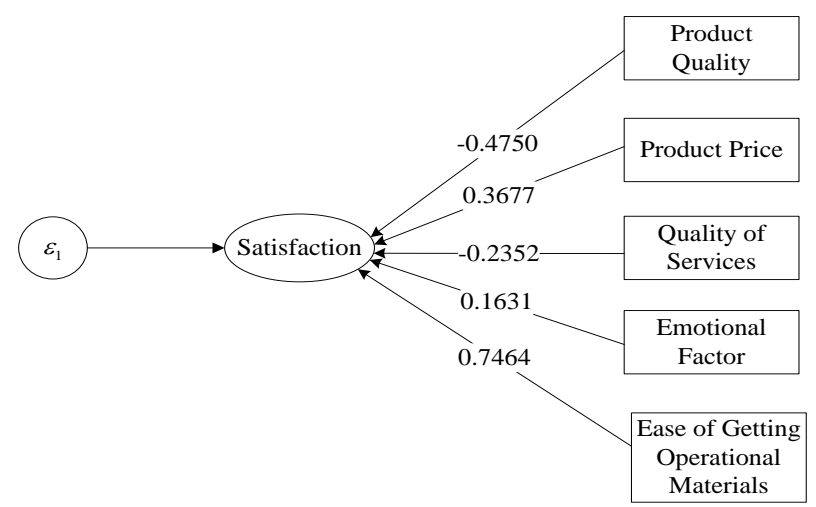

Figure 3. First Order of Outer Model Satisfaction Variable

Based on Table 5, the component loading value or the weight of each indicator can be presented in Figure 4. Figure 3 is an external model for the satisfaction variable of the first-order model. The component loading value in Figure 3 is the value that forms the gratitude variable for each indicator.

\subsubsection{Path Analysis}

\section{Parameter Estimation}

Estimation of parameters in the path analysis is done using Ordinary Least Square (OLS). Table 6. is the result of parameter estimation using OLS.

Table 5. Path Coefficient

\begin{tabular}{|c|c|c|c|}
\hline Variable & Coefficient & P-value & Effect \\
\hline$\beta_{X_{1} Y_{1}}$ & 0.00062 & 0.3979 & Insignificant \\
\hline$\beta_{X_{1} Y_{2}}$ & -0.4632 & $<0.001$ & Significant \\
\hline$\beta_{Y_{1} Y_{2}}$ & 0.4357 & $<0.001$ & Significant \\
\hline
\end{tabular}

Based on Table 5. gives the results that, the demographic variable (X1) does not significantly influence the gratitude variable (Y1), where the path coefficient shows the value of 0.00062 and p-value 0.3979 , because the p-value is more than the critical value $(5 \%)$ then not significant. The results of the subsequent analysis showed that there was a significant influence but the direction of the negative relationship, namely the influence of demographic variables on the variable of farmer satisfaction. The path coefficient shows the value of -0.4632 and the p-value of $<0.001$. The third test result shows a significant positive relationship between the variables of gratitude and farmer satisfaction variables because it has a p-value of $<0.001$ and a path coefficient of 0.4357 . That is, with the increasing gratitude of farmers will have an impact on high farmer satisfaction. Figure 4 shows the research result model for the first-order model.

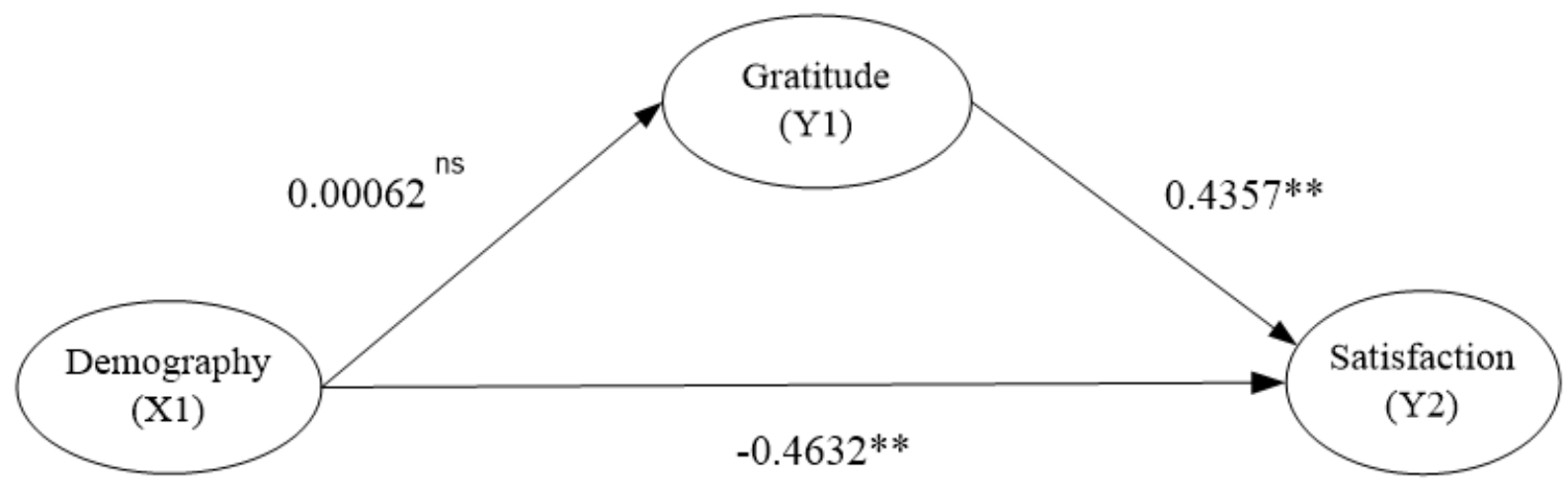

Figure 4. First Order of Research Results 


\section{Linearity Test}

The method used to carry out linearity testing is the Ramsey Reset Test. The results of the linearity test can be summarized in Table 6 . With a $5 \%$ confidence level, it can be seen that the relationship between variables satisfies the linearity assumption.

Table 6. Linearity Assumption Test Results

\begin{tabular}{|c|c|c|}
\hline Variable & P-value & Result \\
\hline X1 vs Y1 & 1.000 & Linear \\
\hline X1 vs Y2 & 0.8272 & Linear \\
\hline Y1 vs Y2 & 0.04612 & Linear \\
\hline
\end{tabular}

\section{Coefficient of Total Determination}

The coefficient of total determination $\left(\mathrm{R}^{2}\right)$ is 0.8714 , meaning that the diversity of data (farmer satisfaction) that can be explained by the model in the first-order analysis is $87.1 \%$ while the remaining $12.9 \%$ is explained by other variables not contained in the model.

\section{Trimming Theory}

The trimming method is the validity of the path analysis, namely by removing the path that is not significant. The final model formed after testing the hypothesis with the bootstrap approach can be seen in Figure 5.

$$
Z_{Y_{2}}=-0.463 Z_{X_{1}}+0.436 Z_{Y_{1}}
$$

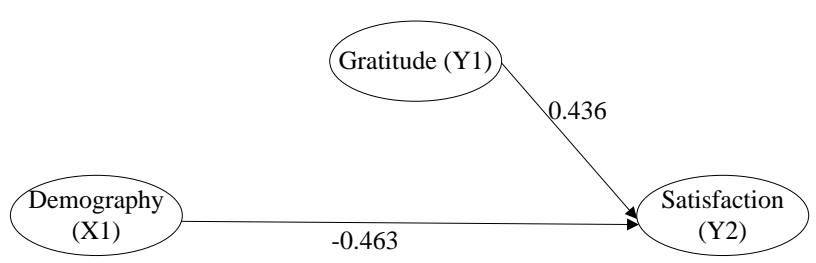

Figure 5. Trimming Model of First Order

\subsection{Second-Order Analysis}

In this second-order analysis, the measurement of the model involves indicators and items.

\subsubsection{Measurement Model (Outer Model)}

\section{Gratitude Variable}

Measurement of the variable of gratitude uses factor analysis. To find out which indicators and items are the greatest in reflecting the gratitude variable, it can be seen through the factor loading value as follows.

$$
\begin{gathered}
Y_{1.1}=-0.5182 F_{Y_{1.1 .1}}+0.0350 F_{Y_{1.1 .2}}+0.6945 F_{Y_{1.1 .3}} \\
-0.4979 F_{Y_{1.1 .4}} \\
Y_{1.2}=-0.4113 F_{Y_{1.2 .1}}+0.4910 F_{Y_{1.2 .2}}+0.1827 F_{Y_{1.2 .3}} \\
-0.7052 F_{Y_{1.2 .4}}-0.2429 F_{Y_{1.2 .5}} \\
Y_{1.3}=0.5990 F_{Y_{1.3 .1}}+0.3318 F_{Y_{1.3 .2}}+0.3520 F_{Y_{1.3 .3}} \\
-0.6381 F_{Y_{1.3 .4}}
\end{gathered}
$$

\begin{tabular}{|c|c|c|c|}
\hline Indicator & $\begin{array}{c}\text { Factor } \\
\text { Loading }\end{array}$ & Item & $\begin{array}{l}\text { Factor } \\
\text { Loading }\end{array}$ \\
\hline \multirow{4}{*}{$\begin{array}{c}\text { Sense of } \\
\text { Appreciation (Y1.1) }\end{array}$} & \multirow{4}{*}{-0.4113} & Y1.1.1 & -0.5182 \\
\hline & & Y1.1.2 & 0.0350 \\
\hline & & Y1.1.3 & 0.6945 \\
\hline & & Y1.1.4 & -0.4979 \\
\hline \multirow{5}{*}{$\begin{array}{l}\text { Positive Feelings } \\
\text { (Y1.2) }\end{array}$} & \multirow{5}{*}{0.4910} & Y1.2.1 & -0.4113 \\
\hline & & Y1.2.2 & 0.4910 \\
\hline & & Y1.2.3 & 0.1827 \\
\hline & & Y1.2.4 & -0.7052 \\
\hline & & Y1.2.5 & -0.2429 \\
\hline \multirow{4}{*}{$\begin{array}{c}\text { Expression of } \\
\text { Gratitude (Y1.3) }\end{array}$} & \multirow{4}{*}{0.1827} & Y1.3.1 & 0.5990 \\
\hline & & Y1.3.2 & 0.3318 \\
\hline & & Y1.3.3 & 0.3520 \\
\hline & & Y1.3.4 & -0.6381 \\
\hline
\end{tabular}

$$
Y_{1}=-0.4113 F_{Y_{1.1}}+0.4910 F_{Y_{1.2}}+0.1827 F_{Y_{1.3}}
$$

Table 7. Component loadings of Gratitude Variable

The measurement results show that with the second-order approach the indicator that has the strongest loading factor is positive feelings, thus positive feelings dominate in forming farmers' gratitude.

Based on Table 7. it can be seen that the indicator of the sense of appreciation has the highest loading factor value, Y1.1.3 (realizing the harvest comes from God). This means that the level of sense of appreciation felt by farmers will look even stronger if farmers are better able to realize the yields obtained are a gift from God and hard work during farming. Furthermore, the positive feelings indicator has the highest loading factor value, Y1.2.4 (feeling happy with the harvest). Then it indicates that the higher the happiness a farmer has in receiving a crop can reflect the level of positive feelings the better. Meanwhile, the item that dominates in the expression of gratitude indicator is Y1.3.4 (appreciating the help of others), so it can be interpreted that the expression of gratitude from farmers will be higher if the farmer can appreciate the assistance of others.

The diversity explained by factor loading on the indicator of the sense of appreciation is 0.3419 which means that the information described by the items reflected by the sense of appreciation indicator is $34.19 \%$. Furthermore, the model can explain the positive feeling indicator by $27.29 \%$, and the rest is explained by other factors. Meanwhile, the expression of gratitude indicator can be explained by the model by $7.72 \%$, the remaining $92.28 \%$ is explained by other factors.

Based on Table 7, the factor loading value of each item and indicator can be presented in Figure 6. Figure 6 is the outer model for the second-order model of the gratitude variable. The factor loading value in Figure 6 is a reflection of the gratitude variable for each of the indicators. 


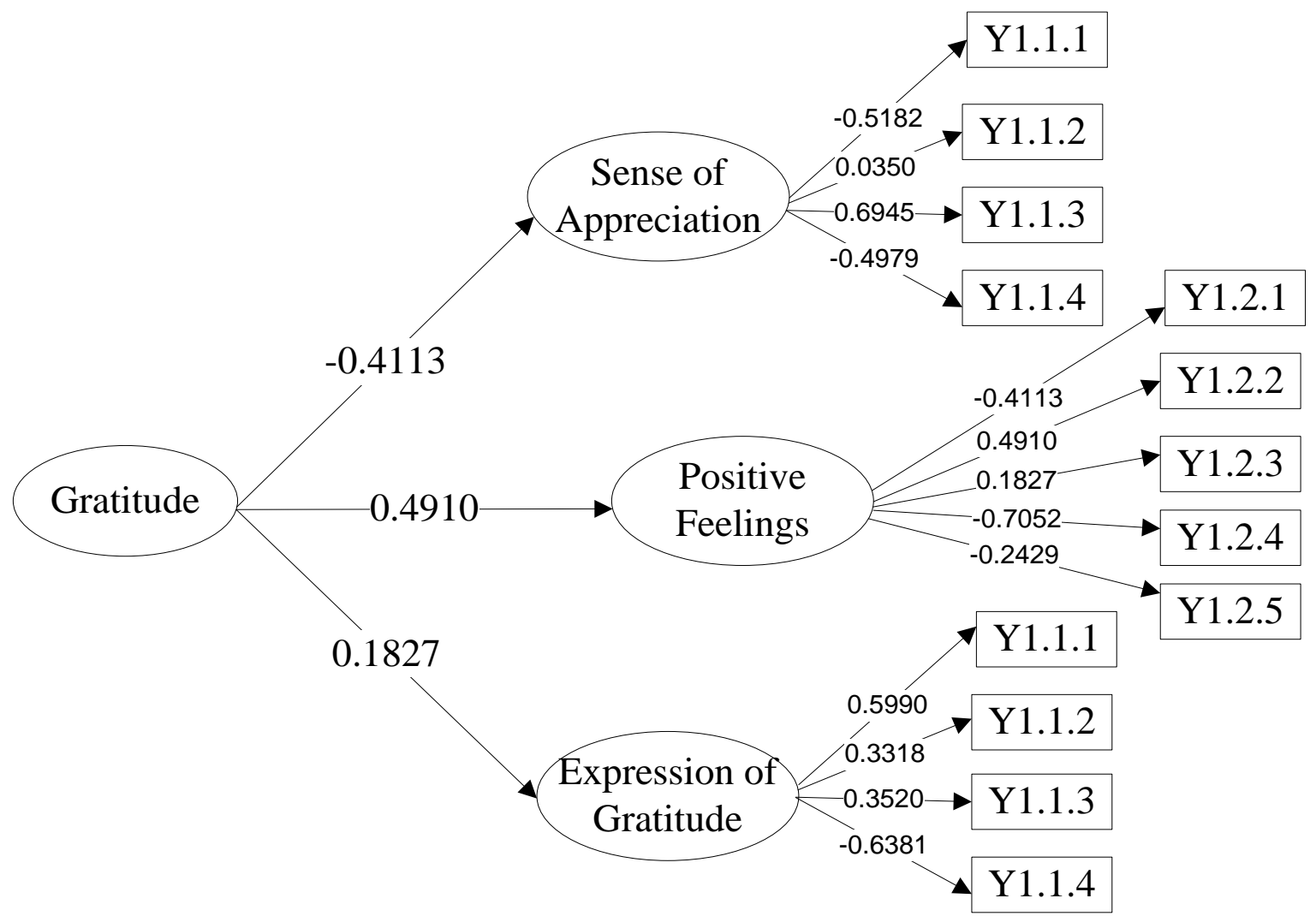

Figure 6. Second-Order of Outer Model Gratitude Variable

\section{Farmers Satisfaction Variable}

The measurement of satisfaction variables uses principal component analysis (PCA). Furthermore, component weights are obtained so that the main component analysis model can be formed to obtain component scores as input from path analysis. The following are the measurement models for each indicator.

Measurement models of product quality indicator:

$$
P C_{1}=0.5521 Y_{2.1 .1}+0.6253 Y_{2.1 .2}-0.5515 Y_{2.1 .3}
$$

Measurement models of product price indicator:

$$
P C_{1}=0.640 Y_{2.2 .1}-0.4015 Y_{2.2 .2}+0.6545 Y_{2.2 .3}
$$

Measurement models of quality of service indicator:

$$
P C_{1}=-0.388 Y_{2.3 .1}+0.8549 Y_{2.3 .2}+0.3442 Y_{2.3 .3}
$$

Measurement models of emotional factor indicator:

$$
P C_{1}=-0.4228 Y_{2.4 .1}-0.8092 Y_{2.4 .2}+0.4080 Y_{2.4 .3}
$$

Measurement models of ease of getting materials indicator:

$$
P C_{1}=-0.6988 Y_{2.5 .1}+0.0554 Y_{2.5 .2}+0.7131 Y_{2.5 .3}
$$

\begin{tabular}{|c|c|c|c|}
\hline Indicator & $\begin{array}{c}\text { Component } \\
\text { loadings }\end{array}$ & Item & $\begin{array}{c}\text { Component } \\
\text { loadings }\end{array}$ \\
\hline \multirow{3}{*}{$\begin{array}{l}\text { Product Quality } \\
\text { (Y2.1) }\end{array}$} & \multirow{3}{*}{-0.4472} & Y2.1.1 & 0.5521 \\
\hline & & $\mathrm{Y} 2.1 .2$ & 0.6253 \\
\hline & & $\mathrm{Y} 2.1 .3$ & -0.5515 \\
\hline \multirow{3}{*}{ Product Price (Y2.2) } & \multirow{3}{*}{0.8944} & $\mathrm{Y} 2.2 .1$ & 0.6406 \\
\hline & & $\mathrm{Y} 2.2 .2$ & -0.4015 \\
\hline & & $\mathrm{Y} 2.2 .3$ & 0.6545 \\
\hline \multirow{3}{*}{$\begin{array}{l}\text { Quality of Service } \\
\text { (Y2.3) }\end{array}$} & \multirow{3}{*}{0.0001} & $\mathrm{Y} 2.3 .1$ & -0.3881 \\
\hline & & $\mathrm{Y} 2.3 .2$ & 0.8549 \\
\hline & & $\mathrm{Y} 2.3 .3$ & 0.3442 \\
\hline \multirow{3}{*}{$\begin{array}{l}\text { Emotional Factor } \\
\qquad(\mathrm{Y} 2.4)\end{array}$} & \multirow{3}{*}{0.0002} & Y2.4.1 & -0.4228 \\
\hline & & $\mathrm{Y} 2.4 .2$ & -0.8092 \\
\hline & & $\mathrm{Y} 2.4 .3$ & 0.4080 \\
\hline \multirow{3}{*}{$\begin{array}{c}\text { Ease of Getting } \\
\text { Operational } \\
\text { Materials (Y2.5) }\end{array}$} & \multirow{3}{*}{0.0004} & $\mathrm{Y} 2.5 .1$ & -0.6988 \\
\hline & & $\mathrm{Y} 2.5 .2$ & 0.0554 \\
\hline & & $\mathrm{Y} 2.5 .3$ & 0.7131 \\
\hline
\end{tabular}

Measurement models of Farmers Satisfaction Variable:

$$
\begin{array}{r}
P C_{1}=-0.4472 Y_{2.1}+0.8944 Y_{2.2}+0.0001 Y_{2.3} \\
+0.0002 Y_{2.4}+0.0004 Y_{2.5}
\end{array}
$$

Table 8. Component loadings of Farmers Satisfaction Variable

Based on Table 8. it can be seen that the measurement results show with the second-order item approach that has the largest component loading (weight) on the product quality indicator is Y2.1.2 (increased harvest weight). Furthermore, items that have the largest component loading (weight) in the product price indicator are Y2.2.1 (harvest prices are competitive) and Y2.2.3 (no inflation). 
The quality of service indicator has the strongest measuring item, Y2.3.2 (good kiosk service). Another result shows that the item that dominates in strengthening the emotional factor indicator is Y2.4.2 (having anxiety). The ease of getting operational materials indicator has the strongest item informing the indicator, namely item Y2.5.3 (a large number of operational materials). With the second-order approach, an indicator that can form a greater farmer satisfaction variable is the product price indicator. This means that the low level of satisfaction of farmers depends on the strength of the product price of the yield obtained by farmers.

The diversity explained by factor loading on the product quality indicator is 0.3879 . Furthermore, the model can explain the product price indicator of $41.58 \%$, and the rest is formed by other factors. Meanwhile, the indicator of the quality of service can be formed by the model of $40.54 \%$, the remaining $59.46 \%$ is explained by other factors. In addition, the information explained by items formed by emotional factor indicators was $37.03 \%$. The ease of getting an operational indicator can be formed by the model by $39.93 \%$, the rest is explained by other factors.

Based on Table 8, the component loading value or the weight of each item and indicator can be presented in Figure 7. Figure 7 is an external model for the satisfaction variable of the first-order model. The component loading value in Figure 7 is the value that forms the gratitude variable for each item and indicator.

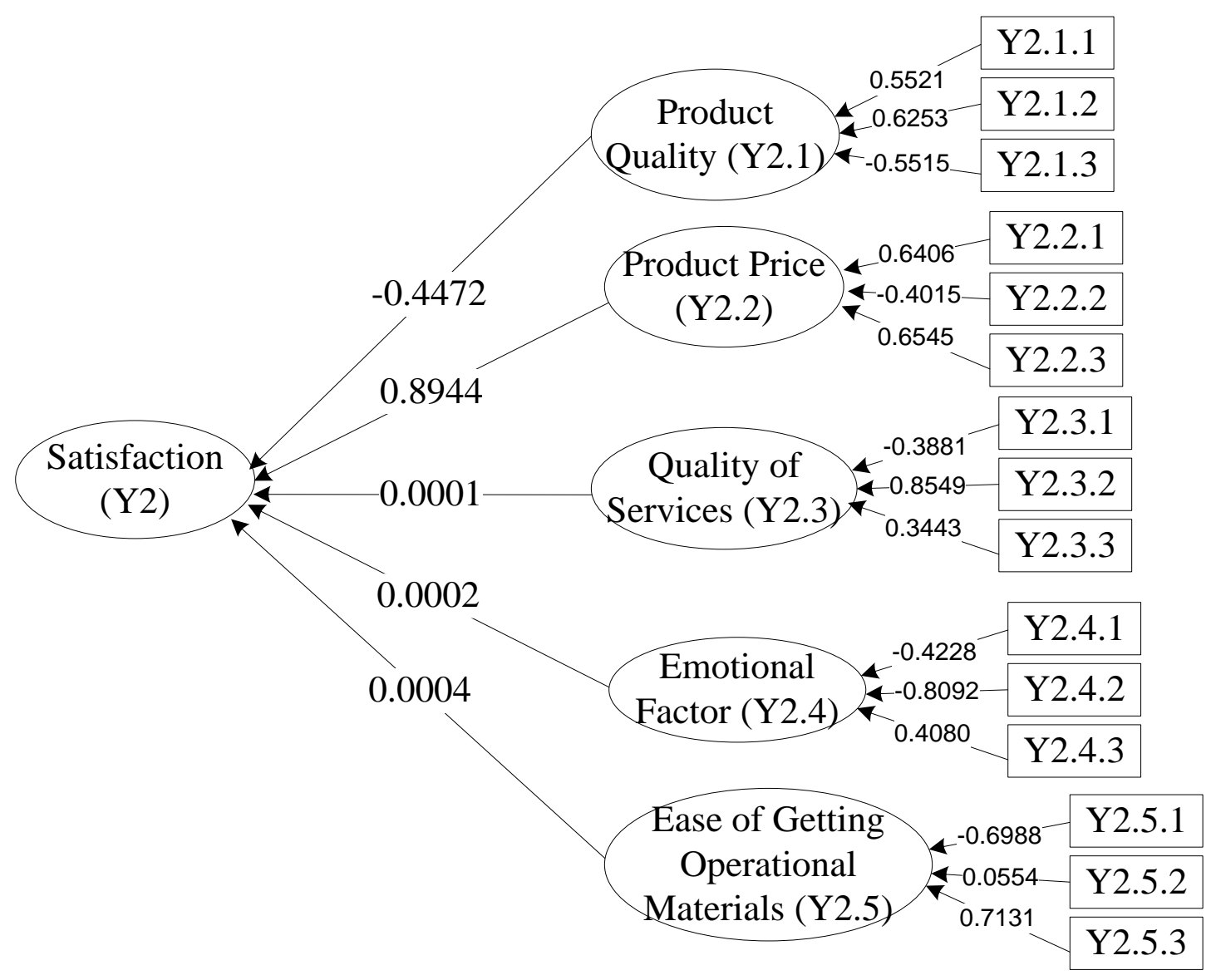

Figure 7. Second-Order of Outer Model Satisfaction Variable 


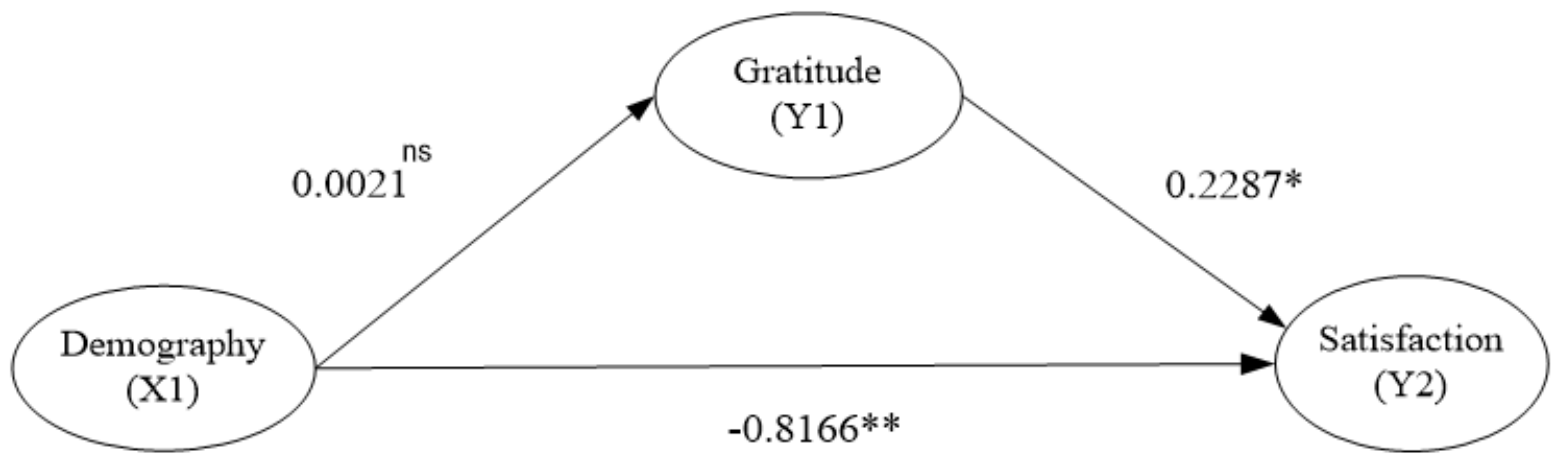

Figure 8. Second-Order of Outer Model Satisfaction Variable

\subsubsection{Path Analysis}

\section{Parameter Estimation}

Estimation of parameters in the path analysis is done using Ordinary Least Square (OLS). Table 9. is the result of estimating the parameters in the second-order analysis.

Table 9. Path Coefficient

\begin{tabular}{|c|c|c|c|}
\hline Variable & Coefficient & P-value & Effect \\
\hline$\beta_{X_{1} Y_{1}}$ & 0.0021 & $<0.001$ & Insignificant \\
\hline$\beta_{X_{1} Y_{2}}$ & -0.8166 & $<0.001$ & Significant \\
\hline$\beta_{Y_{1} Y_{2}}$ & 0.2286 & 0.0232 & Significant \\
\hline
\end{tabular}

Based on Table 9. gives the results that, the demographic variable (X1) does not significantly influence the gratitude variable (Y1), where the path coefficient shows the value of 0.0021 and $p$-value $<0.001$, because the $p$-value is more than the critical value $(5 \%)$ then not significant. The results of the subsequent analysis showed that there was a significant influence but the direction of the negative relationship, namely the influence of demographic variables on the variable of farmer satisfaction. The path coefficient shows the value of -0.8166 and the p-value of $<0.001$. The third test result shows a significant positive relationship between the variables of gratitude and farmer satisfaction variables because it has a p-value of 0.023 and a path coefficient of 0.2286 . That is, with the increasing gratitude of farmers will have an impact on high farmer satisfaction. Figure 8. shows the research result model for the first-order model.

\section{Linearity Test}

Table 10. Linearity Assumption Test Results

\begin{tabular}{|l|c|l|}
\hline Variable & P-value & Result \\
\hline X1 vs Y1 & 1.000 & Linear \\
\hline X1 vs Y2 & 0.8278 & Linear \\
\hline Y1 vs Y2 & 0.0461 & Linear \\
\hline
\end{tabular}

The method used to carry out linearity testing is the Ramsey Reset Test. The results of the linearity test can be summarized in Table 10. With a confidence level of 5\%, it can be seen that the relationship between variables satisfies the linearity assumption.

\section{Coefficient of Total Determination}

The coefficient of total determination $\left(\mathrm{R}^{2}\right)$ is 0.5495 , meaning that the diversity of data (farmer satisfaction) that can be explained by the model in the first-order analysis is $54.95 \%$ while the remaining $45.05 \%$ is explained by other variables not contained in the model.

\section{Trimming Theory}

The trimming method is the validity of the path analysis in the second-order analysis, namely by removing the path that is not significant. The final model formed after testing the hypothesis with the bootstrap approach can be seen in Figure 9.

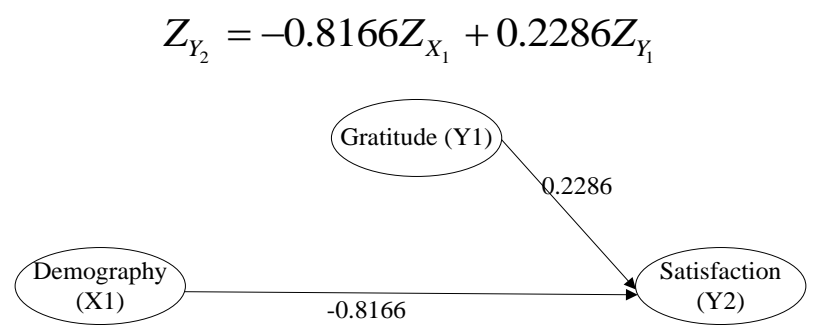

Figure 9. Diagram of Research Results

\section{Comparison of First Order Models with Second Orders}

The analysis results that have been displayed in the first-order analysis model and the second-order analysis above can be drawn as follows.

Table 11. Comparison of Model Goodness

\begin{tabular}{|c|c|c|}
\hline Model & $\begin{array}{c}\text { Coefficient of } \\
\text { Determination }\left(\mathbf{R}^{\mathbf{2}}\right)\end{array}$ & $\begin{array}{c}\text { Mean Squared Error } \\
\text { (MSE) }\end{array}$ \\
\hline First Order & $87.14 \%$ & 37.882 \\
\hline $\begin{array}{c}\text { Second } \\
\text { Order }\end{array}$ & $54.95 \%$ & 189.839 \\
\hline
\end{tabular}

Based on Table 11. the results are obtained that the first-order model is better than the second-order model because it has the lowest MSE value and the highest $\mathrm{R}^{2}$. 
The goodness of the model in each analysis is shown by the coefficient of determination $\left(\mathrm{R}^{2}\right)$ value of the first-order model and the second-order model. In the first-order model produces a coefficient of determination $\left(\mathrm{R}^{2}\right)$ of 0.8714 , meaning that the demographic and gratitude variables of farmers can explain the farmer satisfaction variable by $87.14 \%$, while the rest is explained by other variables outside the model. Furthermore, the second-order model produced the coefficient of determination $\left(\mathrm{R}^{2}\right)$ value of 0.5495 , this shows that the diversity of farmer satisfaction variables that can be explained by demographic and gratitude variables is $54.95 \%$.

MSE is a measure of the quality of the estimator where the value is always non-negative and a value close to zero is better. MSE is the average squared difference between the estimated value and the actual value. The result of this analysis is the mean squared error (MSE) value of the first order of 37,882. Meanwhile, the mean squared error (MSE) value for the second-order model is higher than the first order that is equal to 189,839 , so the first-order model is better. To find out how much efficiency the path analysis model uses first order by calculating the relative efficiency of MSE second order compared to MSE first order.

$$
\begin{aligned}
\text { Re lative Efficiency }(E R) & =\frac{M S E_{\text {sec ond-order }}}{M S E_{\text {first-order }}} \\
= & \frac{189.83}{37.881}=5.01
\end{aligned}
$$

Based on the results of the relative efficiency of the second-order model to the first order of 5.01 means that the first-order model is five times more efficient than the second-order model.

\section{Discussion}

Based on the Mean Squared Error (MSE) and Coefficient of Determination $\left(\mathrm{R}^{2}\right)$ values of each model, the Farmer Satisfaction modeling in East Java Province is more accurate and efficient using the First Order model than using the Second Order model. In general, the research applies first-order analysis, because based on factor analysis each time conducting a factor analysis it is possible to lose information by around $30 \%$. Then with the second-order application only leaves $49 \%$ information, while $51 \%$ is wasted or lost due to too much-reduced data diversity. This has the consequence that the relationship between variables is insignificant. The solution that can be done is that the data analysis process can be done with first order, even though the measurement process / structural model involves a second-order [10]. In detail, the analysis process is the data from items averaged so that the indicator data are obtained. The average calculation process does not reduce the information contained in the data. However, having the weaknesses of all items is seen to have the same weight as measuring indicators or variables or not being able to know which items are the most dominant (only able to know the most dominant indicators).

The results of the path analysis for the first order and second-order models produce the same results that there is a significant positive effect between the gratitude variables on the farmer satisfaction variable. That is, the more gratitude felt by farmers, the satisfaction will be increased by East Java Farmers. Things that need to be considered in the high and low levels of farmers' gratitude are positive feelings, especially the happy feelings that farmers have in receiving the harvest. Farmers in East Java Province are thankful that they are widely implemented, and not only concerned with certain aspects, but the aspects of Sense of Appreciation and Expression of Gratitude must also still be considered in shaping Farmers' Gratitude better.

Furthermore, the strongest aspect that reflects the Farmer Satisfaction variable is Product Price and Product Quality. The product quality aspect is related to the quality of the subsidized fertilizer itself and also its benefits for increasing rice production. On the other hand, aspects of Product Price include: (1) High-value and competitive yields, (2) Yields tend to be stable, and (3) No price inflation occurs when selling products. Empirically these aspects are already in good condition, so there is a need for efforts to maintain and at the same time be accompanied by efforts to repair or increase. Bearing in mind, satisfied farmers will increase their participation in development programs. In other words, farmer satisfaction is an important aspect of the development process in Indonesia so that it can run smoothly and successfully.

In the demographic variables, the most dominant indicator or the strongest in measuring the demographic variables is the indicator of age and length of work. So that the demographics of farmers can be more prominent if the age and length of work of farmers in East Java are always the government's attention. On the other hand, the test results showed that demographic variables did not significantly influence gratitude variables. However, demographic variables have a significant effect on the direction of the negative relationship with farmer satisfaction variables.

\section{Conclusions}

In this study, demographic variables of a mixed scale (nominal, ordinal, interval, and ratio) can be applied to the path analysis by first performing a method of measuring latent variables using principal nonlinear component analysis. Next, the measurement of the variable of gratitude uses factor analysis. This is because the gratitude variable has a reflective indicator. Meanwhile, the measurement of farmer satisfaction variables uses principal component analysis (PCA) because it is a formative model.

The results of Farmer Satisfaction modeling in East Java using the first-order model show more accurate and five 
times more efficient than the second-order model because it has a lower MSE value and higher $\mathrm{R}^{2}$. The results of the path analysis for the first order and second-order models produce the same results that there is a significant positive effect between the gratitude variables on the farmer satisfaction variable. That is, the more gratitude felt by farmers, the satisfaction will be increased by East Java Farmers. On the other hand, the test results showed that demographic variables did not significantly influence gratitude variables. However, demographic variables have a significant effect on the direction of the negative relationship with farmer satisfaction variables.

\section{REFERENCES}

[1] Astutik, S. (2018). Multivariate Analysis: Theory and Application with SAS. Universitas Brawijaya Press.

[2] Budiantara, I.N. (2005). Model Keluarga Spline Polinomial Truncated Dalam Regresi Semiparametrik, Jurnal Berkala MIPA Vol. 15(3).

[3] Chatfield, C., \& Collins, A. (1981). Introduction to multivariate analysis (Vol. 1). CRC Press.

[4] Chin, W., \& Hubona, G. (2006). Structural equation modeling (SEM) using PLS-Graph software: A tool for quantitative researchers analyzing path-based models. AMCIS 2006 Proceedings, 547.

[5] Dillon, W. R. \&amp; Goldstein, M. (1984). Multivariate Analysis Methods and Applications. New York: John Wiley dan Sons

[6] Eubank, R. L. (1999). Nonparametric regression and spline smoothing. CRC press.

[7] Fernandes, A. A. R., Solimun, \&amp; Arisoesilaningsih, E. (2017). Estimation of Spline Function in Nonparametric Path Analysis Based on Penalized Weighted Least Square (PWLS). AIP Conference Proceeding. 1913(1).

[8] Gifi, A. (1990). Nonlinear multivariate analysis. Wiley.

[9] Hair, J. F., Black, W. C., Babin, B. J., dan Anderson, R. E. (1998). Multivariate Data Analysis. New Jersey: Prentice Hall.

[10] Hair, Jr., J.F., R.E Anderson, R.L. Tatham and W.C. Black. (2010). Multivariate Data Analysis with Reading. New York: Macmillan Pub. Company.

[11] Härdle, W. (1990). Applied nonparametric regression (No. 19). Cambridge university press.

[12] Hutahayan, B., Fernandes, A. A. R., Yanti, I., Astuti, A. B., \& Amaliana, L. (2019, June). Mixed Second Order Indicator
Model: The First Order Using Principal Component Analysis and The Second Order Using Factor Analysis. In IOP Conference Series: Materials Science and Engineering (Vol. 546, No. 5, p. 052073). IOP Publishing.

[13] Johnson, R. A., \& Wichern, D. W. (2002). Applied multivariate statistical analysis (Vol. 5, No. 8). Upper Saddle River, NJ: Prentice hall.

[14] Joreskog, K.G. \& Dag Sorborn. 1993. LISREAL 8: Structural Equation Modeling with the Simples Command Language. Chicago: Scientific Software International Inc.

[15] Kock, N. (2016). Advantages of nonlinear over segmentation analyses in path models. International Journal of E-Collaboration (Ijec), 12(4), 1-6.

[16] Krzanowski, W. (2000). Principles of multivariate analysis (Vol. 23). OUP Oxford.

[17] Land, K. C. (1969). Principles of path analysis. Sociological methodology, 1, 3-37.

[18] Lee, J.-M., Yoo, C., Choi, S. W., Vanrolleghem, P. A., \& Lee, I.-B. (2004). Nonlinear process monitoring using kernel principal component analysis. Chemical Engineering Science, 59(1), 223-234.

[19] Li, C. C. (1975). Path Analysis-a primer. California: The Boxwood Press.

[20] Lumenta, C. Y., Kekenusa, J. S., \& Hatidja, D. (2012). Path analysis of the factors causing crime in the city of Manado. Jurnal Ilmiah Sains, 12(2), 77-83.

[21] Ostertagová, E. (2012). Modelling using polynomial regression. Procedia Engineering, 48, 500-506.

[22] Rencher, A. C. (2003). Methods of multivariate analysis (Vol. 492). John Wiley \& Sons.

[23] Simamora, B. (2005). Multivariate marketing analysis. Gramedia Pustaka Utama.

[24] Solimun, M. S. (2002). Structural Equation Modelling (SEM) Lisrel and Amos. Malang: Fakultas MIPA Universitas Brawijaya.

[25] Solimun. (2010). Multivariate Analysis of Structural Modeling with Partial Least Square Method-PLS. Malang: CV. Citra Malang.

[26] Solimun, Adji, A. R. F., \& Nurjannah, N. (2017). Multivariate Statistical Methods for Structural Equation Modeling (SEM). Malang: UB Press

[27] Solimun, Fernandes, A.A.R., \& Cahyoningtyas, R.A. (2020). The Implementation of Nonlinear Principal Component Analysis to Acquire the Demography of Latent Variable Data (A Study Case on Brawijaya University Students). Mathematics and Statistics, Vol. 8(4), pp.437-442

[28] Tatsuoka, M. M., \& Lohnes, P. R. (1988). Multivariate analysis: Techniques for educational and psychological research. Macmillan Publishing Co, Inc. 